\title{
Exercise Therapy for Total Tear of Rotator Cuff: A Case Report
}

\author{
Authors' Affiliation: \\ Department of Sports Medicine, Rasoul \\ Akram Hospital, Iran University of \\ Medical Sciences. Tehran, Iran
Authors' Contribution
A Concept/Design
B Acquisition of Data
C Data Analysis / Interpretation
D Manuscript Preparation
E Critical Revision of the Manuscript
F Funds Collection
G Approval of the Article \\ * Corresponding Author; \\ Address: Rasoul Akram Hospital, Niayesh \\ St., Satarkhan Ave., Tehran, Iran \\ E-mail: parisanejati@yahoo.com \\ Received: Jun 11,2013 \\ Accepted: Nov 11, 2013 \\ Available Online: Dec 11, 2013
}

\author{
Parisa Nejati* ${ }^{\text {ABDD }}$, MD; Faramarz Akbari ${ }^{\text {ABG }}$, MD
}

\begin{abstract}
Background: Shoulder pain is one of the most common problems in ages older than 60 years of age. Rotator cuff pathology is the most common etiology of shoulder pain. Most of rotator cuff pathologies are treated conservatively in old ages and exercise therapy is not an accepted intervention for management of rotator cuff tear yet.

Case presentation: The case was a man of 53 years age with shoulder pain who had total tear of supraspinatus tendon and biceps tendinitis in the right shoulder. He had regularly gone swimming, mountain climbing and running in the last 10 years. The case was managed by exercise therapy for 3 months and physical modalities for 20 sessions. Shoulder pain and his function and right shoulder range of motion increased after 3 months. Para clinical findings did not change after treatment, though. The improvements continued 15 months after the beginning of the treatment.
\end{abstract}

Conclusion: Exercise therapy was very effective for improving pain and function in total tear of supraspinatus tendon and tendinitis of biceps.

Key words: Exercise Therapy; Shoulder Pain; Rotator Cuff; Tendinitis

\section{INTRODUCTION}

$\mathrm{D}$ isorders of the shoulder are extremely common. Almost $30 \%$ of people experiencing shoulder pain at some stage of their lives ${ }^{[1]}$. For people over 65 years of age shoulder pain is the most common musculoskeletal problem ${ }^{[2]}$. In addition to the high incidence, shoulder dysfunction is often persistent and recurrent with 54\% of sufferers reporting on-going symptoms after 3 years ${ }^{[3]}$. Pathology of the rotator cuff and subacromial bursa are considered to be the principal causes of pain and symptoms arising from the shoulder. What is of concern is that shoulder pathology is associated with substantial dysfunction and morbidity ${ }^{[4]}$.

There are few studies about the efficacy of conservative treatment. Even though current evidence is not sufficient to allow definitive conclusions on conservative treatment of rotator cuff tears, subacromial shoulder pain is commonly treated nonoperatively with exercise therapy, non steroidal antiinflammatory drugs (NSAIDS), corticosteroid injection, shock-wave therapy, and other approaches ${ }^{[5-}$ 7].

The results of randomized controlled trials and systematic reviews of interventions for rotator cuff pathology and shoulder pain suggest that exercise may be an effective treatment, ${ }^{[8-15]}$ but there is a definite need for well-planned randomized controlled trials investigating the efficacy of exercise in the management of full thickness and massive rotator cuff tears.

According to the research results, it remains hard to draw firm evidence-based conclusions for effectiveness of non-surgical interventions to treat rotator cuff tear. More research is clearly needed to clarify the best management in such patients ${ }^{[15-18]}$. 


\section{CASE PRESENTATION}

The patient was a 53-year-old man who was suffering from a moderate pain in his right shoulder because of lifting a heavy object. Two days after the incident, due to falling on an outstretched hand while climbing, he felt a very severe pain in the same area. Three days after the second incident, he visited Rasool-E-Akram Hospital's Sports Medicine Clinic. He reported a severe pain in his right shoulder in the first visit (Visual Analog Scale (VAS) = 9-10). In evaluation with goniometer, right shoulder had 150 degree forward flexion and 130 degree painful abduction. Internal rotation could be done very painfully, not suitable for goniometer measurement. The other movements of the shoulder were relatively normal and the left shoulder was perfectly normal. Tests on the right shoulder showed positive result for Neer impingement sign, Empty Can test, Hawkins Kenedy test and Speed test. In evaluating the neck, range of motion was normal and there was no pain. In patient's posture evaluation, there was thoracic kyphotic posture, forward head posture, right scapular winging; and tightness in right upper trapezius and levator scapulae muscles.

During the mentioned 5 days, no treatment had been used other than manual massage on the suffered shoulder. There was no disease in the patient's medical history and he didn't use any specific medication.

His sport history showed that in the last 10 years he had regularly gone swimming twice a week for 2 hours each session, he had gone mountain climbing approximately 10 hours per week, and ran 20 kilometers at least 2 days a week.

In ultrasonography of the right shoulder there was a complete tear in supraspinatus tendon and the other cuff tendons were suspicous for rupture and fluid was reported around the biceps tendon which was in favor of biceps tendonitis.

In MRI without contrast on the patient's shoulder, a 17-mm gap was reported in insertion of supraspinatus tendon. Fluid in joint space of sub-acromial sub-deltoid was also reported. Rupture in the other cuff tendons and biceps tendon was not reported in MRI. Bone marrow edema was evident in greater tuberosity.
After the first visit, 10 sessions of physical therapy modalities (TENS, US, Superficial heat) were done once every two days, each session for 45 minutes. Beside modality, $15 \mathrm{mg}$ Meloxicam tablet was prescribed for the patient twice per day, which was taken for only the three first days by the patient. An exercise program began from the fifth session of physical therapy modalities ( 2 weeks after injury).

Exercise program was under the physician's supervision twice per week in the first month and trained exercises were performed daily at home. Patient's cooperation during 6 months of treatment was excellent and he performed taught exercises with high precision. In the initial days of exercise program, the patient consulted two shoulder surgeons, both of whom suggested surgery on cuff tendons. However, because of his fears he decided to perform exercise program for 6 months. If the exercise program had failed, he would have undergone surgery.

In the first phase of the exercise program, passive ROM exercises were done in the form of forward flexion, internal rotation, external rotation, and abduction. Pendulum exercise, isometric exercises on the shoulder, chin tuck, back extension, shrug exercise were done in this phase too. All of these exercises were done 30 times daily. Stretching exercises for posterior capsule, anterior capsule, the inferior capsule, and trapezius muscle were done twice per day. Each time 5 repetitions were done for 15 seconds. During the first month of treatment, training exercises were supervised twice a week for one hour under the supervision of the physician. If there was a problem in conducting exercises by the patient, necessary recommendations were given. In other days the exercises were done at home.

After obtaining full passive ROM in the involved shoulder and reducing pain, strength training for rotator cuff was initiated from the second month as the second phase of the treatment. The phase included scaption exercise (0 -30 degree abduction), internal, external rotator strengthening exercise $(0$ degree of abduction, scaption (0-60 degree), internal and external rotators (45 degree of abduction), and biceps (0-90 degree) exercise. Three weeks later exercises of the third phase started and strength training and stretching exercise on neck were conducted. 
At the beginning of the third month of therapy, strength training for periscapular muscles was added to the previous exercises. Wall push up, wall push up with medicine ball, push up, push up plus were conducted as 3 sets 10 repetitions daily beside other exercises. Cuff strength training severity was increased gradually during the next months as 3 sets 15 repetitions and abduction was done in higher angles. Exercises on medicine ball were done as push up, quadruped exercise, diagonal exercise. At the beginning of each treatment sport session, 10-15 min systematic warm-up as brisk walking was done. At the end of each treatment session, ice was applied on the right shoulder for $20 \mathrm{~min}$. After three months of exercise therapy, the patient was allowed to swim twice per week. Given a slight pain in full abduction, ha was advised not to have full stroke.

At the end of 6-month exercise program, patient's pain reached to 0 according to VAS. In the evaluation after the 6-month exercise program, there was a negative result for Neer impingement sign, Empty Can test, Hawkins Kenedy test, and Speed test; however, winging of scapula persisted. These results continued to the 9th month (to this report's time). In goniometer examination, there were 146 degree abduction and 170 degree forward flexion in the right shoulder.

At the end of the 6 months of treatment, ultrasonography of the shoulder showed no difference compared to the time before the treatment. In MRI without contrast on the patient shoulder, a 14-mm gap was reported in insertion of supraspinatus tendon. The fluid in joint space of sub-acromial sub-deltoid was reported. Bone marrow edema was evident in greater tuberosity. After termination of the program, the patient initiated mountain climbing twice per week, and he swam twice per week each time for 2 hours.

\section{DISCUSSION}

Results suggest a very satisfactory improvement in pain and inability of the shoulder despite of the changes in para-clinical results. These results verify the positive impact of conservative treatment in total tear of rotator cuff. According to the reports of the previous studies ${ }^{[12-19]}$, there is evidence in favor of positive impact of exercise in treatment of total tear of rotator cuff tendons. In most of the studies it has been emphasized that further studies are required for supporting the results.

Haahr et al ${ }^{[12]}$ and Brox et al ${ }^{[13,14]}$ reported similar results for exercises and surgical treatment after 1 and 6 months and 2.5 years, respectively. The described successful rate of conservative treatment according to Longo UG et al. study varies widely from 33 to $92 \%$ [17].

According to Baydar M study, in order to prevent increasing size of full rupture of rotator cuff tendons surgery is recommended for individuals older than 60 years, otherwise, follow-up and periodical follow-up is recommended for diagnosis of increased size. According to the recommended pattern, periodic ultrasonography can also be done to track the extent of tendon rupture in the cases.

According to a study by Baydar et al. (2009) in Turkey ${ }^{[19]}$, results of supportive treatment including exercise, NSAIDs and Physical Therapy Modalities, and motion correction of the full rupture of the cuff tendons reported very high recovery in 55\% of people and high recovery in $45 \%$ after 6 months. They investigated reduced pain and function improvement, both subjectively and objectively, which continued until 1 and 3 years after treatment initiation.

In our case, 15 months after treatment initiation, the patient was evaluated and no pain in the shoulder was reported. Shoulder examination tests were also negative. According to the patient, among trained exercises, the following are still conducted: Push up, push up plus, neck strengthening exercises, scaption, and biceps strengthening.

It is better to follow-up the patient 3 years after the treatment in order to study lasting effects of conservative therapy. One of the limitations in this study was that the patient function wasn't investigated by a questionnaire, as subjective, and it was evaluated qualitatively.

Patient's home was very close to the patient's treatment site. On the other hand, since the patient was retired, he could attend any treatment or supervision 
session and he had a very satisfactory cooperation. It can be concluded that familiarity and having a history of sport and exercise, and the careful conduction of trained patterns by the patient were very helpful in his treatment outcome. Given the opinion of the therapist, cooperation of the patient in careful conduction of exercises is one of the most important factors in effectiveness of the exercise therapy.

\section{REFERENCES}

[1] Vander Heijden GJ. Shoulder disorders: a state-of-the-art review. Baillieres Best Pract Res Clin Rheumatol 1999;13:287-309.

[2] Taylor W. Musculoskeletal pain in the adult New Zealand population: prevalence and impact. N Z Med J 2005;118(1221):U1629.

[3] Macfarlane GJ, Hunt IM, Silman AJ. Predictors of chronic shoulder pain: a population based prospective study. J Rheumatol 1998; 25(8):1612-5.

[4] Vander Windt DA, Koes BW, Boeke AJ, et al. Shoulder disorders in general practice: prognostic indicators of outcome. Br J Gen Pract 1996;46:519-23.

[5] Hay EM, Thomas E, Paterson SM. A pragmatic randomised controlled trial of local corticosteroid injection and physiotherapy for the treatment of new episodes of unilateral shoulder pain in primary care. Ann Rheum Dis 2003;62:394-9.

[6] Gomoll AH, Katz JN, Warner JJ, Millett PJ. Rotator cuff disorders: recognition and management among patients with shoulder pain. Arthritis Rheum 2004;50:3751-61.

[7] Harniman E, Carette S, Kennedy C, Beaton D. Extracorporeal shock wave therapy for calcific and noncalcific tendonitis of the rotator cuff: a systematic review. J Hand Ther 2004;17:132-51.

[8] Ainsworth R, Lewis JS. Exercise therapy for the conservative management of full thickness tears of the rotator cuff: a systematic review. Br J Sports Med 2007;41:200-10.

[9] Desmeules F, Cote CH, Fremont P. Therapeutic exercise and orthopedic manual therapy for impingement syndrome. A systematic review. Clin J Sports Med 2003;13:176-82.

[10] Grant HJ, Arthur A, Pichora DR. Evaluation of interventions for rotator cuff pathology: a systematic review. J Hand Ther 2004;17: 274-99.

[11] Green S, Buchbinder R, Hetrick S. Physiotherapy interventions for shoulder pain. Cochrane Database Syst Rev 2003;2:CD004258.

[12] Haahr JP, Ostergaard S, Dalsgaard J, et al. Exercises versus arthroscopic decompression in patients with subacromial impingement:a randomised, controlled study in 90 cases with a one year follow up. Ann Rheum Dis 2005;64:760-4.

[13] Brox JI, Staff PH, Ljunggren AE, Brevik JI. Arthroscopic surgery compared with supervised exercises in patients with rotator cuff disease (stage II impingement syndrome). BMJ 1993;307:899-903.

[14] Brox JI, Gjengedal E, Uppheim G, et al. Arthroscopic surgery versus supervised exercises in patients with rotator cuff disease (stage II impingement syndrome): a prospective, randomized, controlled study in 125 patients with a $21 / 2$-year follow-up. J Shoulder Elbow Surg 1999;8:102-11.

[15] Littlewood C, Ashton J, Larsen KC, et al. Exercise for rotator cuff tendinopathy: a systematic review. Physiotherapy 2012;98:101-9.

[16] Huisstede BM, Koes BW, Gebremariam L, et al. Current evidence for effectiveness of interventions to treat rotator cuff tears.Man Ther 2011;16:217-30.

[17] Longo UG, Franceschi F, Berton A, et al. Conservative treatment and rotator cuff tear progression .Med Sport Sci 2012;57:90-9.

[18] Safran O, Schroeder J , Bloom R, et al. Natural History of Nonoperatively Treated Symptomatic Rotator Cuff Tears in Patients 60 Years Old or Younger. Am J Sports Med 2011;39:710-4.

[19] Baydar M, Akalin E, Gulbahar S, et al. The efficacy of conservative treatment in patients with full-thickness rotator cuff tears. Rheumatol Int 2009;29:623-8. 